\title{
Immunohistochemical study of sustentacular cells in adrenal medulla of neonatal and adult rats using an antibody against S-100 protein
}

\author{
A.M. Ahmed \\ Department of Anatomy, College of Medicine, King Saud University, Riyadh, Saudi Arabia
}

[Received: 28 April 2016; Accepted: 11 September 2016]

Background: This study was performed to investigate the light microscopic features of sustentacular cells in adrenal medulla in neonatal and adult male albino rats using an antibody against S-100 protein. S-100 expression in sustentacular cells is considered a reliable cell marker for this type of cells.

Materials and methods: Twenty-four male albino rats were allocated into two groups, neonatal group (1 week old, 12 rats) and adult group (3 months old, 12 rats). Paraffin sections of the adrenal glands were immunostained for the expression of S-100 protein.

Results: The results demonstrated differences in distribution, arrangement and structure of sustentacular cells in adrenal medulla in neonatal and adult rats. All sustentacular cells of adrenal medulla in all animals showed intense immunoreactivity for S-100 protein in their nuclei, perikarya, and cytoplasmic processes. Most of S-100 immunopositive sustentacular cells in adrenal medulla of neonatal rats are few, dispersed, small in size, and oval in shape with thin short bipolar cytoplasmic processes. These cells in adult rats are more numerous, larger in size, and stellate in shape with numerous slender, longer branched cytoplasmic processes. Conclusions: This study indicated that adrenal medullary sustentacular cells showed obvious morphological postnatal changes with aging suggesting structural and functional maturation. (Folia Morphol 2017; 76, 2: 246-251)

Key words: adrenal medulla, sustentacular cells, S-100 protein, immunohistochemistry, rat

\section{INTRODUCTION}

The adrenal medulla is an endocrine organ of neural origin located in the central region of the adrenal gland [19]. It is composed of three different neural crest-derived cell types including chromaffin cells, ganglion cells, and sustentacular cells $[1,3,5,16,17]$. Chromaffin cells constitute most of the adult adrenal medulla [11]. The adrenal medulla also contains a small number of ganglion cells interspersed among the chromaffin cells [1]. In addition, the adrenal medulla also contains sustentacular cells; Schwann-like cells that closely envelop adrenal chromaffin cells without a basal lamina [3]. The adrenal medullary sustentacular cells are demonstrated by their expression of S-100 protein as well as its characteristic electron microscopic appearance [3].

It has been suggested that the adrenal medullary sustentacular cells reveal characteristics similar to sup-

Address for correspondence: Associate Professor A.M. Ahmed, Department of Anatomy, College of Medicine, King Saud University, PO Box 2925 (28), Riyadh 11461, Saudi Arabia, tel: +966(11)4670809, fax: +966(11)4671300, e-mail: alymahmed53@gmail.com 
porting cell types located in other endocrine organs, such as the pituitary pars distalis and the pineal glands $[7,22]$. It was stated that the adrenal medullary sustentacular cells closely resemble glial cells of the peripheral nervous system in immunohistochemical, ultrastructural, and also functional properties [9]. The glial cells are considered to be supporting cells [23]. In addition, these cells participate in the modulation of the neuronal activity in the central nervous system and of the adrenal medullary chromaffin cells [10]. The presence of S-100 protein, which is related to calcium metabolism, has been demonstrated in these cell types [6]. It has been postulated that the adrenal medullary sustentacular cells might regulate the calcium levels in the extracellular compartment [13]. It is proved that calcium ion participates in the mechanism of liberation of catecholamines, mainly noradrenaline [4]. It has been detected that the adrenal medullary sustentacular cells are mainly located and remarkably higher in the regions of the noradrenaline chromaffin cells than the regions of adrenaline chromaffin cells [21].

S-100 protein is a calcium-binding acidic protein originally isolated from the brain [9]. Astrocytes of the central nervous system, satellite cells of the peripheral ganglia, and Schwann cells are immunoreactive for S-100 protein $[2,20]$. This protein has, therefore, been regarded as a common marker for glial cells, including Schwann cells [9]. It has been suggested that adrenal medullary sustentacular cells are modified Schwann cells, because these cells express immunoreactivity for S-100 [3]. In general, S-100 protein has already been shown to be a specific marker of adrenal medullary sustentacular cells as well as the other associated cells of glial nature $[9,15,24]$.

In spite of the functional significance of adrenal medullary sustentacular cells, omission of their description in almost all textbooks is unjustifiable. The present study investigated the regional localisation, arrangement, and structure of adrenal medullary sustentacular in neonatal and adult male albino rats by immunohistochemical method at the light microscopic level using an antibody against S-100 protein.

\section{MATERIALS AND METHODS}

\section{Experimental animals}

Twelve newborn albino Swiss rats and twelve adult rats ( 3 months old) were obtained from the Animal Care Centre at the College of Medicine, King Saud University, Riyadh, Kingdom of Saudi Arabia. Rats were housed and maintained under standard controlled environmental conditions at a temperature of $25 \pm$ $\pm 2{ }^{\circ} \mathrm{C}$ on 12 -h light/dark cycle. All rats including adult ones and mothers of newborn rats were acclimatized for 1 week and maintained with free access to standard pelleted rat chow and tap water, ad libitum.

All experimental procedures followed were conducted in accordance with the standards established by the Guidelines for the Care and Use of Laboratory Animals of the College of Medicine Research Centre (CMRC) at King Saud University and conform with the Guide for the Care and Use of Laboratory Animals published by the National Institutes of Health (NIH in USA).

\section{Experimental procedure}

After acclimatisation for 1 week, all rats were perfused under ether anaesthesia with Ringer's solution followed by $4 \%$ paraformaldehyde in $0.1 \mathrm{M}$ phosphate buffer. The animals were dissected and the adrenal glands were excised and postfixed in $4 \%$ paraformaldehyde in phosphate buffer overnight. Then, the adrenal glands were processed to prepare $4-\mu \mathrm{m}$-thick paraffin sections for immunohistochemical study.

\section{Immunohistochemistry}

Immunostaining of the paraffin sections of neonatal and adult adrenal glands for detection of S-100 protein was performed using streptavidin-biotinylated horse radish peroxidase (S-ABC) method (Novalink Max Polymer detection system; Novocastra Laboratories, Newcastle, UK). Sections were deparaffinised with xylene and hydrated through decreasing concentrations of ethanol. Then, sections were incubated in a solution of $3 \% \mathrm{H}_{2} \mathrm{O}_{2}$ in distilled water for $5 \mathrm{~min}$ to inhibit endogenous peroxidase activity and washed in Tris-buffered saline (TBS, pH 7.6) (Sigma-Aldrich) twice, 5 min each. Non-specific binding to antibodies was blocked by incubation with protein block for $5 \mathrm{~min}$ (Novocastra) and rinsed with distilled water and TBS. Sections were incubated with primary antibody against S-100 protein (rabbit polyclonal antibody, at a dilution of 1:500) (Abcam, Cambridge, UK) for $1 \mathrm{~h}$ at room temperature. Sections were washed in TBS for 3 times, each for $3 \mathrm{~min}$. Then, sections were incubated with biotinylated anti-rabbit lgG (Novocastra) for $30 \mathrm{~min}$, washed in TBS for 3 times, each for 3 min, incubated with Novolink polymer (Novocastra) for $30 \mathrm{~min}$ and washed in TBS for 3 times, each for $3 \mathrm{~min}$. Peroxidase was detected with chromogen solution of diaminobenzidine (DAB) substrate 
(Novocastra) for $10 \mathrm{~min}$. Finally, Sections were washed in distilled water for $10 \mathrm{~min}$, counterstained with Mayer's haematoxylin, dehydrated, and mounted in DPX (Dysterene, Plasticizer, Xylene). For negative control sections, the same procedure was followed but with omission of incubation with the primary antibody against S-100 protein and replacing it with normal (non-immune) rabbit Ig. All negative control sections revealed negative reactions.

\section{Image analysis}

High-resolution whole-slide digital scans of S-100 immunostained sections were created with a ScanScope scanner (Aperio Technologies, Inc.). The digital slide images were then viewed and analysed using the viewing and image analysis tools of Aperio ImageScope software (Aperio Technologies, Inc.). Five areas, each with the fixed size of $137,000 \mu \mathrm{m}^{2}$, were randomly selected per section. To quantify the immunopositive reactions, the colour deconvolution (colour separation) algorithm (Aperio Technologies, Inc.) was set up (by colour calibration) to detect and quantify only the brown colour of DAB positive staining. The algorithm was then run on the selected area to measure the percentage of immunopositive reactions relative to the measured areas. The analysis output results were finally exported to Excel sheets and subjected to statistical analysis to be compared between neonatal and adult rats.

\section{Statistical analysis}

Data collected were subjected to statistical analysis using IBM SPSS Statistics version 22 software. The values were expressed as mean \pm standard error of mean (SEM). The means of the area per cent of S-100 immunopositive reaction were compared between the two studied groups using student's t-test. Differences were considered significant when $p$ value was less than or equal to 0.05 .

\section{RESULTS}

Sections of adrenal medulla from neonatal and adult male albino rats were immunostained to express S-100 protein. All adrenal medullary chromaffin cells, which were arranged in clusters and cords, were negatively immunostained with S-100 protein antibody. On the other hand, the adrenal medullary sustentacular cells showed intense immunoreactivity for S-100 protein in their nuclei, perikarya, and cytoplasmic processes.

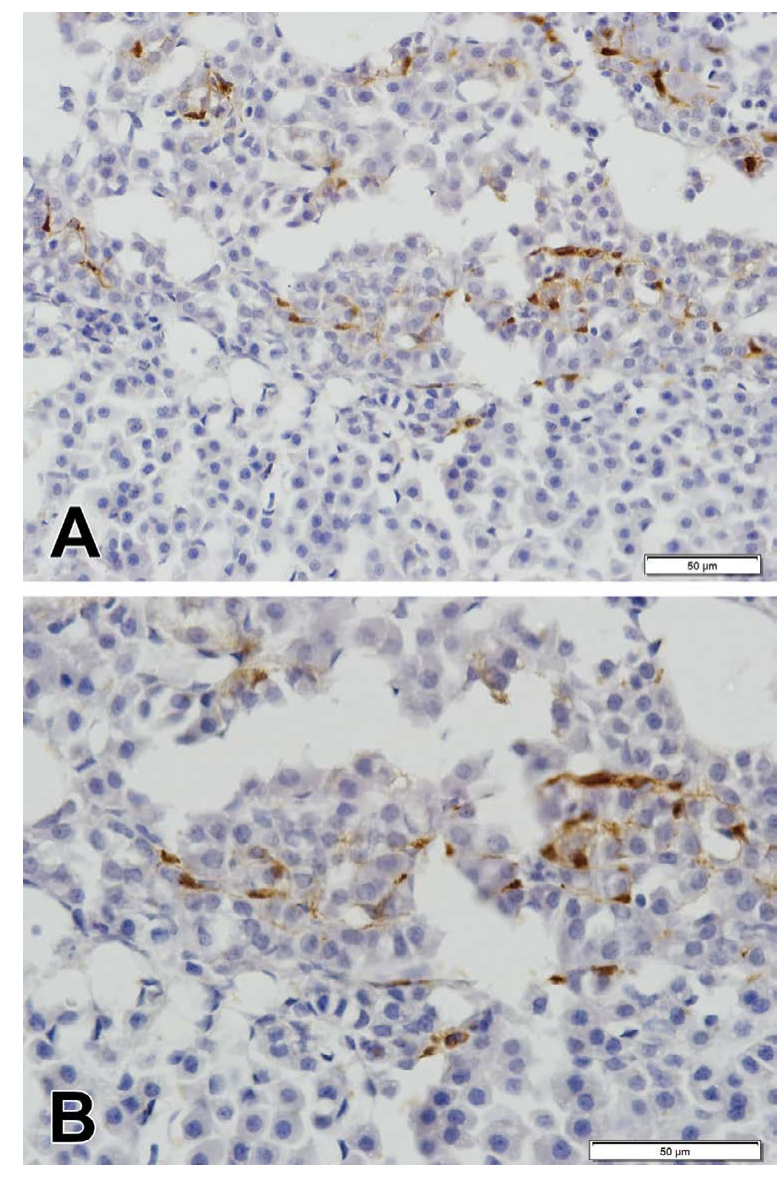

Figure 1. Low (A) and high (B) magnification photomicrographs of S-100 immunostained section of adrenal medulla from neonatal rat (1 week old) showing few sustentacular cells with intense immunopositive nuclei, perikarya, and cytoplasmic processes. Perikarya are apparently small with thin short bipolar processes. These processes terminate freely without forming a network. Scale bar $=50 \mu \mathrm{m}$.

Sections of adrenal medulla from neonatal rats showed few dispersed sustentacular cells with intense S-100 immunoreactivity in their nuclei, perikarya, and the few cytoplasmic processes. Most of these cells were oval with small perikarya and bipolar cytoplasmic processes. These processes were thin, short, less branched, and usually terminating freely without forming a network in between the adrenal chromaffin cells (Fig. 1).

Sections of adrenal medulla from adult rats showed more numerous adrenal medullary sustentacular cells with intense S-100 immunoreactivity in their nuclei, perikarya, and the numerous cytoplasmic processes. These cells were observed scattering and interdigitating in between the adrenal chromaffin cells. Perikarya of most sustentacular cells in this group were larger in size and stellate in shape with 

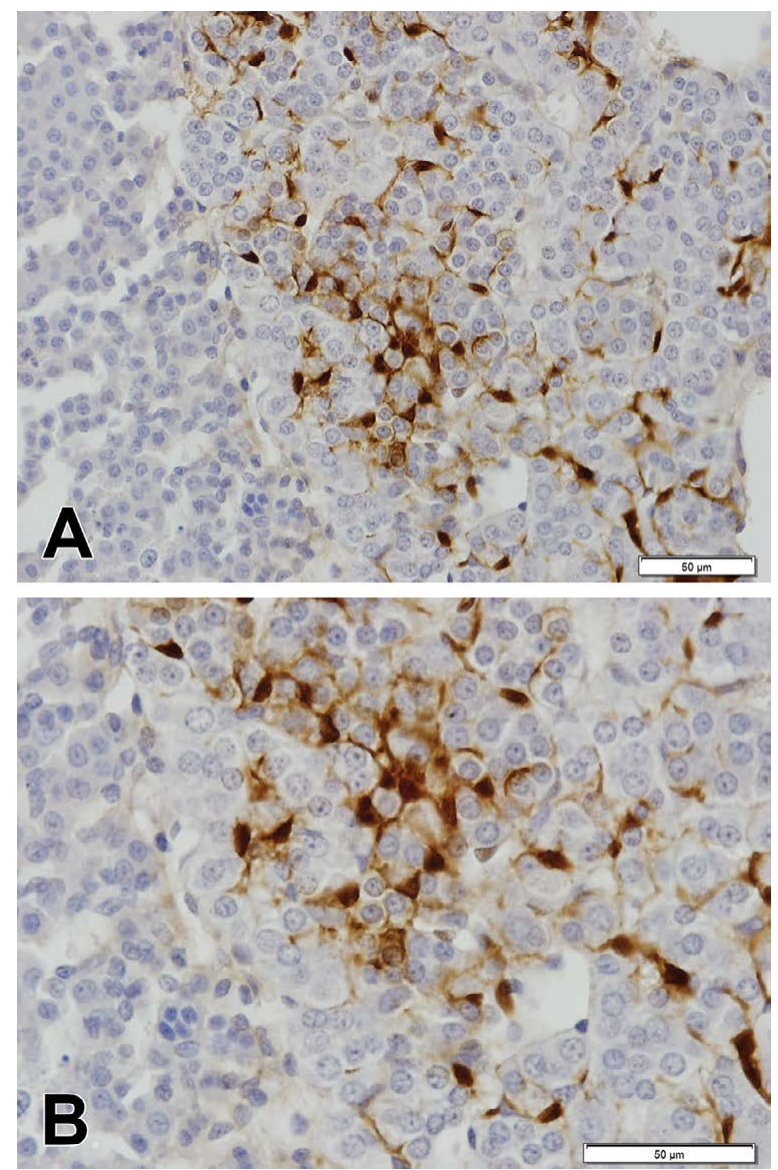

Figure 2. Low (A) and high (B) magnification photomicrographs of S-100 immunostained section of adrenal medulla from adult ( 3 months old) rat showing numerous and larger sustentacular cells with intense immunopositive nuclei, perikarya, and cytoplasmic processes. Perikarya are apparently large and stellate in shape. The cytoplasmic processes are more numerous, long, slender, and more branched. In many regions, these processes terminate forming networks. Scale bar $=50 \mu \mathrm{m}$.

numerous multipolar cytoplasmic processes radiating from the perikarya. Most of these cytoplasmic processes were slender, but longer and more branched and usually terminating forming network in between the adrenal chromaffin cells. Few sustentacular cells in this group were oval in shape with bipolar cytoplasmic processes. Localisation of the sustentacular in adrenal medulla of adult rats was unevenly distributed where certain regions revealed numerous sustentacular cells and other regions contained sparsely localised sustentacular cells (Fig. 2).

Data obtained from the statistical analysis revealed that mean \pm SEM of area per cent of S-100 immunopositivity in sustentacular cells of the adrenal medulla from rats of neonatal group was $5.42 \pm 0.22$; however, this value was significantly increased

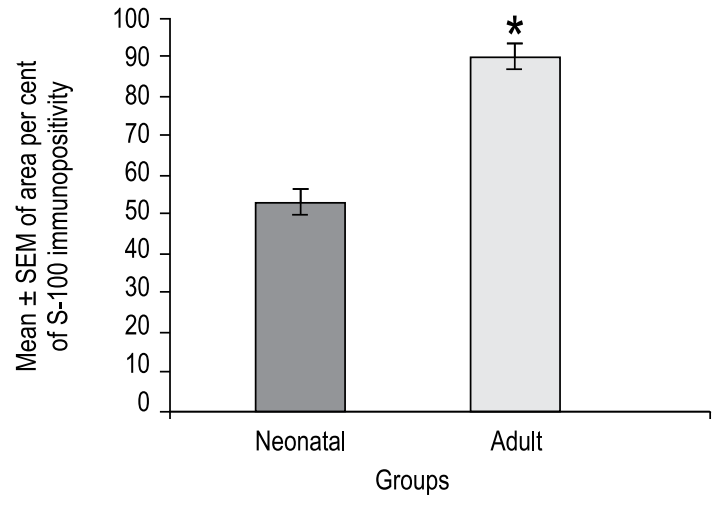

Figure 3. Mean \pm standard error of mean (SEM) of area per cent of S-100 immunopositivity in the adrenal medulla of neonatal and adult groups; *Significant difference at $\mathrm{p} \leq 0.05$.

to $9.01 \pm 0.58$ in adult group ( $p$ value vs. neonatal group: 0.02) (Fig. 3).

\section{DISCUSSION}

The present study demonstrated the expression of the immunohistochemical marker, S-100 protein, in the sustentacular cells of the adrenal medulla of neonatal and adult rats. The immunostaining of the adrenal gland with anti-S-100 protein demonstrated immunoreaction only in the sustentacular cells [11, 19]. Also, Cocchia and Michetti [3] reported that S-100 protein is a specific marker substance for sustentacular cells of the adrenal medulla in the rat. The existence of glial-specific protein S-100 in the adrenal medullary sustentacular cells may suggest that this type of cells is related to neuroglia and Schwann cells in function and metabolism [8]. In accordance, other studies indicated that adrenal medullary sustentacular cells are homologous in nature with Schwann cells and are immunoreactive for S-100 [3, 12].

The present study demonstrated strong immunoreaction for S-100 protein in nuclei, perikarya, and cytoplasmic processes of sustentacular cells in adrenal medulla of both neonatal and adult rats. A previous study has detected S-100 protein immunoreaction in nuclei and cytoplasm of these cells [12].

In the present study, differences in morphologic features including shapes, sizes, and pattern of branching of the sustentacular cells of adrenal medulla from neonatal rats compared with adult rats have been observed. These differences in features suggest that the neonatal sustentacular cells to be still in stage of differentiation $[14,18]$. 
The present study revealed regional differences in the localisation of sustentacular cells in association with chromaffin cells in the adrenal medulla in rats. Suzuki and Kachi [23] found that the extent of cellular association of S-100 immunopositive sustentacular cells with chromaffin cells was remarkably more frequent in noradrenaline-cell regions than in adrenaline-cell regions in the adrenal medulla. Moreover, in noradrenaline-cell region, these more numerous sustentacular cells show extending numerous cytoplasmic processes between noradrenaline chromaffin cells. However, in the adrenaline-cell region, few sustentacular cells with few cytoplasmic processes were detected [23]. The cytoplasmic processes of sustentacular cells ramify in between and encircle the chromaffin cells $[9,19]$. Rodriguez et al. [19] stated that the sustentacular cells may fulfil an important function in the support and regulation of the chromaffin cells, modulating in a way the synthesis and secretion of catecholamines. S-100 protein is believed to be secreted by the sustentacular cells and to act as a trophic factor for the adjoining chromaffin cells in the adrenal medulla [9].

\section{Limitations of the study}

This study did not demonstrate sustentacular cells in foetal adrenal medulla. This study did not investigate quantitative localisation of sustentacular cells in regions of noradrenaline and adrenaline chromaffin cells. This study did not demonstrate the electron microscopic structure of sustentacular cells in adrenal medulla.

\section{CONCLUSIONS}

In summary, the results of the present study demonstrated the differences in arrangement and structure of sustentacular cells in the adrenal medulla in neonatal and adult male albino rats. It could be concluded that adrenal medullary sustentacular cells undergo obvious marked morphological postnatal changes suggesting functional and structural maturation.

Based on the data of the present study, and increasing evidence for the importance of adrenal medullary sustentacular cells, more comprehensive studies should be performed to disclose the functional significance of these cells in correlation with their structure in neonatal and adult stages.

\section{Acknowledgements}

The author gratefully acknowledges the Research Centre, College of Medicine, Deanship of Scientific
Research, King Saud University, Riyadh, Kingdom of Saudi Arabia for the financial support and continuous encouragement.

\section{REFERENCES}

1. Anderson DJ, Axel R. Molecular probes for the development and plasticity of neural crest derivatives. Cell. 1985; 42(2): 649-662, indexed in Pubmed: 3839717.

2. Cocchia D. Immunocytochemical localization of S-100 protein in the brain of adult rat. An ultrastructural study. Cell Tissue Res. 1981; 214(3): 529-540, indexed in Pubmed: 7214465.

3. Cocchia D, Michetti F. S-100 antigen in satellite cells of the adrenal medulla and the superior cervical ganglion of the rat. An immunochemical and immunocytochemical study. Cell Tissue Res. 1981; 215(1): 103-112, indexed in Pubmed: 7226189.

4. Crivellato E, Belloni A, Nico B, et al. Chromaffin granules in the rat adrenal medulla release their secretory content in a particulate fashion. Anat Rec A Discov Mol Cell Evol Biol. 2004; 277(1): 204-208, doi: 10.1002/ar.a.20004, indexed in Pubmed: 14983514.

5. Dagerlind A, Pelto-Huikko $M$, Diez $M$, et al. Adrenal medullary ganglion neurons project into the splanchnic nerve. Neuroscience. 1995; 69(4): 1019-1023, indexed in Pubmed: 8848091.

6. Gonzalez-Martinez T, Perez-Piñera P, Díaz-Esnal B, et al. S-100 proteins in the human peripheral nervous system. Microsc Res Tech. 2003; 60(6): 633-638, doi: 10.1002/ jemt.10304, indexed in Pubmed: 12645010.

7. Heizmann CW, Fritz G, Schäfer BW. S100 proteins: structure, functions and pathology. Front Biosci. 2002; 7(1): 1356-d1368, indexed in Pubmed: 11991838.

8. Iwanaga T, Fujita T. Sustentacular cells in the fetal human adrenal medulla are immunoreactive with antibodies to brain S-100 protein. Cell Tissue Res. 1984; 236(3): 733-735, doi: 10.1007/bf00217246, indexed in Pubmed: 6380742 .

9. Kameda Y. Immunoelectron microscopic localization of vimentin in sustentacular cells of the carotid body and the adrenal medulla of guinea pigs. J Histochem Cytochem. 1996; 44(12): 1439-1449, doi: 10.1177/44.12.8985136, indexed in Pubmed: 8985136.

10. Laming PR, Kimelberg $H$, Robinson $S$, et al. Neuronal-glial interactions and behaviour. Neurosci Biobehav Rev. 2000; 24(3): 295-340, indexed in Pubmed: 10781693.

11. Lloyd RV, Wilson BS. Specific endocrine tissue marker defined by a monoclonal antibody. Science. 1983; 222(4624): 628-630, indexed in Pubmed: 6635661.

12. Lloyd RV, Blaivas M, Wilson BS. Distribution of chromogranin and S100 protein in normal and abnormal adrenal medullary tissues. Arch Pathol Lab Med. 1985; 109(7): 633-635, indexed in Pubmed: 3839362.

13. Mäler L, Sastry M, Chazin WJ. A structural basis for $\$ 100$ protein specificity derived from comparative analysis of apo and $\mathrm{Ca}(2+)$-calcyclin. J Mol Biol. 2002; 317(2): 279-290, doi: 10.1006/jmbi.2002.5421, indexed in Pubmed: 11902843.

14. Mascorro JA, Yates RD. Mitotic cell division in the extraadrenal chromaffin system of various species. J Elec- 
tron Microsc Tech. 1989; 12(4): 323-330, doi: 10.1002/ jemt.1060120405, indexed in Pubmed: 2769435.

15. Owada $Y$, Abdelwahab SA, Kitanaka N, et al. Altered emotional behavioral responses in mice lacking brain-type fatty acid-binding protein gene. Eur J Neurosci. 2006; 24(1): 175-187, doi: 10.1111/j.1460-9568.2006.04855.x, indexed in Pubmed: 16882015.

16. Parker TL, Mohamed AA, Coupland RE. The innervation of the adrenal gland. IV. The source of pre- and postganglionic nerve fibres to the guinea-pig adrenal gland. J Anat. 1990; 172: 17-24, indexed in Pubmed: 1703141.

17. Parker TL, Kesse WK, Mohamed AA, et al. The innervation of the mammalian adrenal gland. J Anat. 1993; 183 ( Pt 2): 265-276, indexed in Pubmed: 8300416.

18. Powers JF, Brachold JM, Schelling K, et al. Potentiation of mitogenesis in adult rat chromaffin cell cultures by immunosuppressive agent FK506. Neurosci Lett. 2004; 356(1): 5-8, indexed in Pubmed: 14746888.

19. Rodriguez $H$, Filippa V, Mohamed F, et al. Interaction between chromaffin and sustentacular cells in adrenal medulla of viscacha (Lagostomus maximus maximus). Anat Histol Embryol. 2007; 36(3): 182-185, doi: 10.1111/j.1439-0264.2006.00732.x, indexed in Pubmed: 17535349.
20. Stefansson K, Wollmann RL, Moore BW. Distribution of S-100 protein outside the central nervous system. Brain Res. 1982; 234(2): 309-317, indexed in Pubmed: 7059833.

21. Suzuki T, Kachi T. Differences between adrenaline and noradrenaline cells in cellular association with supporting cells in the adrenal medulla of the pig: An immunohistochemical study. Neurosci Lett. 1994; 176(2): 217-220, doi: 10.1016/0304-3940(94)90086-8.

22. Suzuki T, Kachi T. Immunohistochemical studies on supporting cells in the adrenal medulla and pineal gland of adult rat, especially on S-100 protein, glial fibrillary acidic protein and vimentin. Kaibogaku Zasshi. 1995; 70(2): 130-139, indexed in Pubmed: 7785412.

23. Suzuki T, Kachi T. Similarities and differences in supporting and chromaffin cells in the mammalian adrenal medullae: An immunohistochemical study. Anat Rec. 1996; 244(3): 358-365, doi: 10.1002/(sici)10970185(199603)244:3<358::aid-ar7>3.0.co;2-u, indexed in Pubmed: 8742700.

24. Yun X, Nourani MR, Abdelwahab SA, et al. Differential localization of brain-type and epidermal-type fatty acid binding proteins in the adrenal gland of mice. Tohoku J Exp Med. 2004; 203(2): 77-86, indexed in Pubmed: 15212142. 